\title{
ATORES SOCIAIS E AÇÕES SOCIAIS EM CRIME INFAME: SOBREVIVI... POSSO CONTAR
}

\author{
Janete Maria De Conto é doutoranda do Programa de Pós-Graduação em Letras, Estudos Linguísticos, da Universidade Federal de \\ Santa Maria e professora da rede pública federal. E-mail: jm.conto@gmail.com \\ Nina Célia Almeida de Barros é professora Dr. do Programa de Pós-Graduação em Letras da Universidade Federal de Santa Maria. \\ ninaceliabarros@uol.com.br
}

\section{RESUMO}

O objetivo deste artigo é apresentar uma análise da representação de atores sociais e de ações sociais identificadas no texto jornalístico: Crime infame: sobrevivi... posso contar. A análise é sustentada pelos princípios do Sistema de Transitividade da Gramática Sistêmico-Funcional de Halliday e Matthiessen (2004) e pelas categorias de representação social - atores e ações - de van Leeuwen (2008).

\begin{abstract}
The purpose of this article is to present an analysis of the representation of social actors and social actions identified in the journalistic text: Infamous crime: I survive... I can tell. The analysis is sustained by the principles of the Transitivity System of Systemic Functional Grammar of Halliday and Matthiessen (2004) and by social representation categories - actors and actions - van Leeuwen (2008).
\end{abstract}

\section{Introdução}

O presente trabalho faz parte das pesquisas referentes ao projeto Lei Maria da Penha: representações sociais em textos midiáticos. O projeto faz parte da Linha de Pesquisa Linguagem no Contexto Social, do Programa de Pós-Graduação em Letras/UFSM e inclui-se no projeto guarda-chuva Análise crítica de gêneros: representações sociais, identidades e multiletramento.

O grupo, responsável por essa linha de pesquisa, trabalha com a pressuposição de que a sociedade a partir da ação dos sujeitos constrói representações sobre si mesma. Essas representações sociais incorporam diversos discursos e organizações linguísticas que, por sua vez, interferem nessas representações em um movimento constante. Assim, linguagem e representações sociais são indissociáveis.

A partir das concepções de Halliday e Matthiessen (2004), sobre Gramática Sistêmico-Funcional (GSF), e de van Leeuwen (2008), sobre representações sociais, pretende-se descrever e analisar léxico e gramaticalmente fragmentos do texto Crime infame: sobrevivi... posso contar, a fim de identificar as categorias de representação de atores e de ações sociais. 
Para realizar a análise, foram adotados os seguintes procedimentos: i - separação das orações que constituem o texto; ii - classificação dos processos, participantes e circunstâncias a partir da proposta do sistema de Transitividade, de Halliday e Matthiessen (2004); iii - classificação de atores sociais e de ações sociais que preenchem os papéis de transitividade no texto; e, iv - análise das formas como atores e ações sociais são representados no texto, de acordo com as categorias sócio-semânticas de van Leeuwen (2008), como inclusão e passivação, ativação e generalização.

O texto, escrito por Tânia Fusco, foi publicado no jornal on-line O Globo, em 25 de novembro de 2005. Esse texto compõe o corpus de análise do trabalho final de doutorado, constituído, inicialmente, por cem (100) textos midiáticos, disponibilizados ao público leitor na internet. Entre os critérios de seleção está a ocorrência da publicação entre 2005 e 2009 e o tema dos textos estabelecer alguma relação com a Lei 11.340/06, conhecida como Maria da Penha e a violência contra a mulher.

Em Crime infame: sobrevivi... posso contar, a autora sintetiza a história de violência doméstica e familiar sofrida por Maria da Penha Maia Fernandes, autobiografada no livro Sobrevivi... posso contar. Além disso, são apresentados comentários a respeito da violência praticada por homens contra suas companheiras, na sociedade brasileira. No ano seguinte à publicação desse texto, foi promulgada a Lei 11.340/06, que em conformidade com o inciso $8^{\circ}$ do artigo 226 da Constituição Federal, tipifica a violência doméstica como uma das formas de violação dos direitos humanos.

Assim, a Lei Maria da Penha, foi elaborada a partir de uma ideologia pautada na igualdade de direitos, para proteger as mulheres que sofrem violência doméstica e familiar e para punir os agressores. No entanto, atualmente, a mídia tem reproduzido esse discurso ideológico e polemizado a questão da sustentabilidade da Lei, também, para proteger homens que sofrem agressões e para punir mulheres agressoras.

\section{Representações Sociais}

Para Fairclough (2001, p. 91), discurso é um modo de agir das pessoas sobre o mundo e sobre a sociedade, bem como uma representação dessa ação social. Nesse sentido, o discurso é composto por três dimensões: prática social, prática discursiva e texto. 
A prática social está relacionada à atuação do indivíduo na sociedade, envolvendo ambientes econômicos, políticos e institucionais particulares que geram o discurso. A prática discursiva diz respeito aos processos de produção, distribuição e consumo dos discursos gerados na prática social. E o texto é a manifestação linguística da prática discursiva (Idem, p. 99-106).

\section{Gramática Sistêmico-Funcional}

Os estudos relacionados à Linguística Aplicada propiciam a afirmação de que a linguagem é um sistema mediador em todos os discursos e que a realidade se constrói pela linguagem. Entre linguagem e sociedade há uma relação dialética, pois uma determina a outra, e as escolhas ou opções realizadas pelo indivíduo no ato comunicativo influenciam e sofrem influência da realidade social que, de certa forma, constituem o contexto de situação e de cultura do evento. Nesse sentido, Pereira e Almeida (2002, p. 245) afirmam que:

Uma realidade se constrói à medida que se fazem opções dentro da língua e à medida que essas opções influenciam, determinam ou legitimam comportamentos na sociedade. (...) a realidade é um reflexo das escolhas que fazemos quando produzimos linguagem, ou ainda, que aquilo a que chamamos de realidade se constrói pela linguagem.

No estudo dos gêneros, reconhecer em um texto aspectos como quem fala, o que se fala e como se fala em um contexto de situação e de cultura, constitui-se preocupação da GSF, pois as escolhas léxico-gramaticais realizadas por um usuário da língua são condicionadas pelo contexto para que esse indivíduo possa realizar e desempenhar suas funções sociais (Ikeda e Vian Jr., 2005, p. 34).

Nos textos específicos de ações que ocorrem em determinados contextos de situação e de cultura, é possível que se percebam certas características textuais / contextuais sinalizadoras de um gênero ou de outro.

Essa concepção está aliada à GSF que integra texto e contexto, pois é possível, por meio dela, perceber quais elementos da estrutura textual são obrigatórios e quais são opcionais a partir da análise da configuração do contexto; desse modo, percebe-se que as escolhas linguísticas realizadas pelo indivíduo são determinadas pelo contexto de situação e de cultura. Motta-Roth e Heberle (2005, p.17) afirmam que: 
Na relação funcional entre linguagem e contexto da situação, cada gênero corresponde a padrões textuais recorrentes (o uso que se faz da linguagem para atingir certos objetivos comunicativos) e contextuais (a situação de experiência humana com a qual determinado registro de linguagem é comumente associado).

As variáveis: campo, relação e modo, da Configuração Contextual (CC) possibilitam a definição do contexto da interação pela linguagem e permitem que se façam previsões sobre determinado texto em um dado contexto, isto é, qualquer texto que possa ser considerado um exemplo em potencial de um gênero específico.

A CC, na perspectiva de Halliday e Hasan (1989, p. 56), é a representação de uma atividade social, cujas características podem ser usadas para fazer previsões acerca de um texto. A CC é formada por três variáveis, que são:

1. Campo: refere-se à natureza da atividade social que está ocorrendo.

2. Relação: refere-se à natureza da conexão entre os participantes (papéis desempenhados por eles e relações existentes entre eles).

3. Modo: refere-se à natureza do meio de transmissão da mensagem. (MottaRoth e Heberle, 2005, p. 15).

Na GSF, a CC é a representação de uma atividade social, cujas características podem ser usadas para fazer previsões acerca de um texto. A cada uma das variáveis da CC está relacionada uma Metafunção, respectivamente, a Ideacional, a Interpessoal e a Textual. Essas Metafunções formam a Estrutura Potencial do Gênero (EPG) (Halliday e Hasan, 1989).

A CC e a EPG estão sintetizadas no Quadro 1.

\begin{tabular}{|c|c|}
\hline $\begin{array}{l}\text { CONFIGURAÇÃO CONTEXTUAL } \\
\text { (CC) }\end{array}$ & $\begin{array}{l}\text { ESTRUTURA POTENCIAL DO GÊNERO } \\
\text { (EPG) }\end{array}$ \\
\hline $\begin{array}{l}\text { Campo } \\
\text { Natureza da atividade social. }\end{array}$ & $\begin{array}{l}\text { Metafunção Ideacional } \\
\text { Escolhas léxico-gramaticais dos interlocutores. }\end{array}$ \\
\hline 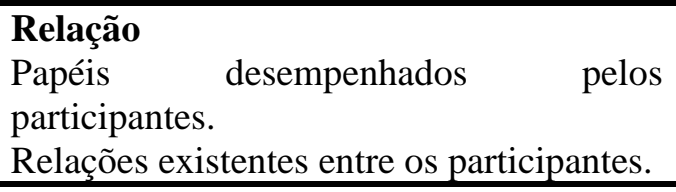 & $\begin{array}{l}\text { Metafunção Interpessoal } \\
\text { Maneira como os interlocutores usam a } \\
\text { linguagem para interagir socialmente. }\end{array}$ \\
\hline $\begin{array}{l}\text { Modo } \\
\text { Natureza do meio de transmissão da } \\
\text { mensagem. }\end{array}$ & $\begin{array}{l}\text { Metafunção Textual } \\
\text { Relação entre os aspectos semânticos e } \\
\text { gramaticais do texto. }\end{array}$ \\
\hline
\end{tabular}

Quadro 1: Quadro da Configuração Contextual e da Estrutura Potencial do Gênero elaborado com base em Halliday e Hasan (1989) e Motta-Roth e Heberle (2005). 
Por meio da variável campo é possível identificar a atividade social em que as pessoas estão envolvidas e o seu objetivo. A relação mostra quem são os participantes envolvidos e o tipo de relação e a distância social existente entre eles. O modo possibilita investigar e interpretar o papel da linguagem, o canal e o meio utilizado para efetivar a mensagem.

As três variáveis da CC relacionam-se diretamente com as Metafunções Ideacional, Interpessoal e Textual da linguagem, da EPG. O estudo das Metafunções e das Variáveis do Contexto dá conta de especificar os elementos textuais e contextuais, e suas respectivas funções, que compõem um determinado gênero.

Assim, há sempre dois níveis de alcance na análise da representação em orações com sustentação na GSF. Um deles é a contribuição para a compreensão do texto, a análise linguística mostra como e por que o texto significa o que significa. No entanto, o alcance maior está na contribuição para a avaliação do texto, isto é, a análise linguística mostra por que o texto é, ou não é, um texto efetivo para seus propósitos. Nessa perspectiva, proceder à análise de discursos e de textos sem o apoio da GSF é pura e simplesmente comentar sobre o texto (Halliday, 1994, xv).

Neste estudo, a atenção está voltada à variável campo que está diretamente ligada à Metafunção Ideacional.

\subsection{Metafunção Ideacional}

Na Metafunção Ideacional, a oração é vista como representação, ou seja, a oração tem significado como construção de processos baseados na experiência humana. Diz respeito à maneira como as pessoas representam o mundo da linguagem (Fuzer, 2008, p. 91). Essa Metafunção é realizada pelo sistema de Transitividade e conta com três elementos: os participantes, os processos e as circunstâncias (Halliday e Matthiessen, 2004, p. 169).

\subsection{Sistema de Transitividade}

As pessoas utilizam a língua para expressarem a maneira como percebem, sentem, experienciam, representam o mundo. Nessa perspectiva, a oração possibilita modelar a experiência e, é por meio das escolhas dos processos (ações), dos 
participantes (pessoas ou coisas) e das circunstâncias, que os usuários da língua se expressam e se posicionam perante o mundo (Martin e Rose, 2003, p. 68).

Halliday e Matthiessen (2004, p. 177) afirmam que o "processo” é representado por “um grupo verbal” e é a ação propriamente dita. Já os “participantes” são representados por “grupos nominais”, que realizam a ação e, também, são afetados por ela. As “circunstâncias" são representadas por "grupos adverbiais” e sua função é adicionar informações ao processo. Processos, participantes e circunstâncias constituem, portanto, o sistema de Transitividade.

Os processos materiais, verbais, relacionais, mentais, comportamentais e existenciais determinam a classificação dos participantes e das circunstâncias em uma oração. Esses elementos do sistema de Transitividade são responsáveis pela representação de atores e ações sociais no discurso.

\section{Representação de Atores e de Ações Sociais}

Van Leeuwen (2008) propõe uma descrição sócio-semântica minuciosa dos modos pelos quais os atores e as ações sociais podem ser representados. A partir da compreensão da prática social e da prática discursiva, é possível investigar a representação da experiência (atividades e atores sociais) por meio da linguagem em uso. Na interpretação, considerara-se que "as representações incluem ou excluem atores sociais para servir os seus interesses e propósitos em relação aos leitores a quem se dirigem” (p. 28).

A gramática de uma língua, como um sistema de escolhas, constitui um potencial de significados. Para representar suas experiências, por meio da linguagem, as pessoas optam por uma ou outra estrutura. Dependendo dessas escolhas, atores sociais podem ser incluídos ou excluídos nos discursos de diferentes formas (Fuzer, 2008, p.133).

Nessa concepção, os atores sociais são representados como agentes ou como pacientes, porém "não é necessário que haja congruência entre os papéis que os atores sociais desempenham, de fato, em práticas sociais e os papéis gramaticais que lhes são atribuídos” (van Leeuwen, 2008, p. 32). Por isso, sob a perspectiva da representação da experiência é possível investigar as escolhas léxico-gramaticais realizadas, os contextos institucionais e sociais em que se realizam, e, também, o motivo pelo qual essas opções são realizadas, quais os interesses subjacentes a elas e quais propósitos são alcançados. 
As representações sociais correspondem a situações reais de vida, por meio das quais os atores sociais se movem, constroem e explicam sua vida (Fuzer, 2008, p. 87). Assim, van Leeuwen (2008) propõem a exclusão e a inclusão, como principais categorias sociológicas, quanto a atores. A exclusão pode ocorrer por supressão, quando as representações podem excluir totalmente os atores sociais, e, em um segundo plano, por encobrimento, em que as representações excluem parcialmente os atores sociais (p. 52).

A inclusão ocorre por ativação, passivação, generalização, especificação, personalização e impersonalização (Fuzer, 2008, p. 145-147). Quanto ao seu tipo ou definição, categorias de inclusão, como especificação, personalização e impersonalização possuem subdivisões, dependendo do modo como se realizam.

As categorias de ações sociais de van Leeuwen (2008) são: ação, reação, ativação, desativação, agencialização, desagencialiação, abstração, concretização, determinação única e sobredeterminação (p. 73). Assim como as categorias de atores sociais, as de ações sociais também possuem subdivisões conforme a maneira pela qual se realizam. Por exemplo, a desativação pode ocorrer por meio de objetivação ou descritivização, do mesmo modo que a generalização e a destilação podem ser compreendidas como formas de abstração (Idem, p. 69).

A generalização possibilita organizar a taxonomia de composição temporal das ações e reações em um determinado texto. “Generalizações tornam-se evidentes apenas em uma análise das relações semânticas entre diferentes representações da mesma ação e reações dentro de um texto ou comparando textos” (Ibidem). Diante disso, a generalização é uma questão importante em análise crítica do discurso, principalmente, no que se refere a textos que apresentam preocupação em legitimar ou deslegitimar ações e reações que tendem a se destacar em uma escala ampla, incluindo apenas nomes de episódios ou toda a prática social (Ibidem).

\section{Procedimentos Metodológicos}

O objetivo deste trabalho é descrever e analisar léxico e gramaticalmente fragmentos do texto Crime infame: sobrevivi... posso contar, a fim de identificar as categorias de representação de atores e de ações sociais. Para tanto, o texto foi selecionado, considerando-se o critério temático: estar relacionado à violência contra a 
mulher e à Lei Maria da Penha; e, considerando-se o seu contexto de produção, no que diz respeito ao suporte e à época de sua publicação.

Como procedimentos adotados para a análise, inicialmente foram separadas as orações que constituem o texto; após foi realizada a classificação dos processos, participantes e circunstâncias a partir da proposta do sistema de Transitividade, de Halliday e Matthiessen (2004).

Diante dessa categorização, foram classificados os atores sociais e as ações sociais que preenchem os papéis de transitividade no texto. A partir disso, foi realizada a análise das formas como atores e ações sociais são representados no texto, de acordo com as categorias sócio-semânticas de van Leeuwen (2008), como inclusão e passivação, ativação e generalização.

\section{A representação de Atores e de Ações Sociais e suas significações}

Nesta seção, são apresentados os resultados da análise sobre como os participantes de uma prática social, atores sociais, e como as ações sociais podem ser representadas, de acordo com van Leeuwen (2008), em Crime infame: sobrevivi... posso contar. Quanto à organização, esse texto estrutura-se em quatro partes, que por sua vez são constituídos por orações. As orações da primeira parte, especificamente suas organizações no nível lexical e gramatical, sob o prisma sistêmico-funcional, são o foco deste estudo e deverão constituir a base para a análise de outras orações das demais partes do texto.

No primeiro parágrafo, conforme o Excerto 1, a autora do texto apresenta os atores sociais, homem e mulher, envolvidos em uma ação social caracterizada pela violência doméstica e familiar contra a mulher. Os números entre parênteses identificam a oração no decorrer da análise.

\section{Excerto 1:}

(1) Primeiro ele simulou um assalto na casa (2) onde a mulher foi baleada pelas costas. (3) Ela deveria ter morrido, (4) mas sobreviveu (5) paraplégica. (6) Ele não desistiu. (7) Tentou eletrocutá-la na banheira. (8) De novo ela não morreu (9) e, dessa vez, viu (10) e pode testemunhar que (11) o agressor era o próprio marido, Marco Antonio Herredia Viveiros, (12) colombiano, professor universitário de economia, pai dos três filhos da biofarmacêutica Maria da Penha Maia Fernandes.

Ao identificar os processos nos fragmentos do texto, foram separadas as orações e classificados os participantes e as circunstâncias. No Tabela 1 são apresentadas as 
classificações dos processos, sua ocorrência e a escolha lexical realizada nessa construção.

\begin{tabular}{|c|c|c|}
\hline Classificação do processo & Ocorrência & \begin{tabular}{|l|} 
Verbo \\
\end{tabular} \\
\hline Material criativo específico & 1 & simulou (1) \\
\hline \begin{tabular}{|lcr}
$\begin{array}{l}\text { Material } \\
\text { contato }\end{array}$ & transformativo & de \\
\end{tabular} & 2 & foi baleada (2), tentou eletrocutá-la (7) \\
\hline \begin{tabular}{|lcr}
$\begin{array}{l}\text { Material } \\
\text { estado }\end{array}$ & transformativo & de \\
\end{tabular} & 4 & $\begin{array}{l}\text { deveria ter morrido (3), sobreviveu (4), } \\
\text { desistiu (6), morreu (8) }\end{array}$ \\
\hline Mental perceptivo & 1 & $\operatorname{viu}(9)$ \\
\hline Verbal (semiose) & 1 & pode testemunhar (10) \\
\hline Relacional atributivo & 2 & ficou (5 - elíptico),é (12 - elíptico) \\
\hline Relacional de identificação & 1 & era (11) \\
\hline
\end{tabular}

Tabela 1: Classificação e identificação dos processos no primeiro parágrafo de Crime infame: sobrevivi...posso contar.

A Tabela 1 mostra o número elevado de ocorrências de processos materiais, o que caracteriza a prevalência de participantes com papéis gramaticais de atores, e que, por isso, sociologicamente, cumprem papéis ativos. Nessa perspectiva, de acordo com as relações sociais estabelecidas entre os participantes, os atores sociais podem ser representados por ativação, quando exercem papéis ativos na atividade, ou por passivação, quando recebem ou são atingidos pela ação.

Quanto à representação de ações, as ações sociais materiais podem ser: transativas, não transativas e transativas interativas. Em ele simulou um assalto (1) ocorre a ação material transativa. Nessa categoria, o processo material exige um complemento que, de acordo com o sistema de Transitividade da Gramática SistêmicoFuncional, no exemplo, ocorre pela meta um assalto. As ações materiais não transativas não necessitam do participante meta, como em ela não morreu (9). Na ocorrência de uma ação material transativa interativa, como em tentou eletrocutá-la (7), o processo necessita de uma meta humana.

Quanto à representação dos atores, o processo material criativo específico simulou (1) relaciona o participante ator ele à meta um assalto na casa, o que resulta na representação do ator por inclusão do tipo ativação, ou seja, esse ator representa a força ativa na ação. Nessa ação, o ator social está indeterminado, pois ainda não é possível saber quem é ele, o que pode remeter o leitor para fora do texto, em uma referência exofórica, estabelecendo uma relação com uma figura masculina humana. Essa relação 
também pode resultar da oposição à mulher (2). A inclusão por ativação confere ao ator a classificação de agente da ação social, ou agencialização.

O pronome pessoal ele (1) se repete na oração 6 e remete a agressor (11), identificado por ser o alvo da definição em uma categoria de inclusão, em que ocorre especificação do tipo individualização. Essa representação é complementada pelo nome e sobrenome do agressor, caracterizando a inclusão, em que atores são representados em termos de sua identidade única, definida como personalização, que ocorre pela sua nomeação Marco Antonio Herredia Viveiros (12). Do mesmo modo, essas categorias se repetem nos atores mulher (2), ela (3), por ativação, e, na pronominalização eletrocutála (7), na funcionalização biofarmacêutica e na nomeação Maria da Penha Maia Fernandes (12), por passivação, o que determina o mesmo ator como agente ou como paciente em diferentes momentos do texto. Isso confirma que a ativação ocorre quando os atores sociais são representados como forças ativas e dinâmicas em uma atividade, enquanto a passivação ocorre quando os atores são representados submetendo-se à atividade ou como receptores dela.

A exclusão pode ocorrer por supressão ou encobrimento, quando os atores são colocados em segundo plano. Na supressão, não há referências aos atores sociais em questão em qualquer parte do texto. Essa categoria pode se realizar por meio do apagamento do agente da passiva, de orações infinitivas que funcionam como participante gramatical, do apagamento dos atores sociais que se beneficiam de uma atividade, das nominalizações e dos nomes de processo que permitem, igualmente, a exclusão de atores sociais.

No encobrimento, que pode resultar de simples elipses, a exclusão é menos radical, já que os atores sociais excluídos podem não ser mencionados em relação a uma dada atividade, mas são mencionados em outros lugares no texto. Por exemplo, nessa parte do texto que se está analisando, há encobrimento por elipse do pronome ela (4, 5, $9,10)$ e do pronome ele (7).

A oração 2 se organiza por passivação do ator, a locução verbal foi baleada classifica-se como processo material transformativo de contato. Há exclusão por encobrimento com o apagamento do agente da passiva, não se sabe quem praticou a ação, mas subentende-se seja ele (1). No sistema de transitividade, a meta a mulher (2) corresponde à inclusão por passivação, pois o ator social é afetado pela ação. Nesse caso sua função é de paciente. 
O processo material transformativo deveria ter morrido (3) difere de foi baleada (2), pois indica estado e, também, porque caracteriza o ator, como agente, por inclusão. O que categoriza sociologicamente ator e ação por ativação.

O processo verbal do tipo semiose pode testemunhar (10) projeta a oração em que os atores sociais, homem e mulher são incluídos, personalizados por seus nomes próprios acrescidos dos seus sobrenomes, o que os identifica individualmente no universo de homens agressores e de mulheres vítimas de violência no âmbito doméstico e familiar.

A inclusão por categorização ocorre na indicação do grau de parentesco, como em o próprio marido, pai dos três filhos (11) e na funcionalização professor universitário de economia e biofarmacêutica (12). A funcionalização rompe com o conceito pré-estabelecido de que a violência contra a mulher ocorre somente em classes sociais e profissionais menos abastadas e com pessoas de baixo nível intelectual. Com essa narrativa, a autora induz o leitor a conceber os atores desse evento pelo status social e financeiro como integrantes da classe média ou da classe média-alta.

Se, por um lado a autora rompe preconceitos, por outro, ela os alimenta, quando localiza no espaço o ator social agressor (11) pelo atributo de seu adjetivo pátrio colombiano (12). Implicitamente, o valor ideológico fundamentado nesse atributo espacial é negativo, devido à concepção de que na Colômbia, boa parte da população está envolvida em narcotráfico, o que implica na pressuposição de que essas pessoas não estão preocupadas com princípios básicos, como os morais, éticos e legais.

As ações e reações dos atores sociais foram narradas, na primeira e segunda parte do texto, como uma introdução à interpretação crítica da autora sobre a violência praticada contra a mulher. Essas ações e reações, que se subdividem em microações, quanto à organização temporal, estão generalizadas em $a$ história (13), na segunda parte do texto, conforme Excerto 2.

\section{Excerto 2:}

(13) A história aconteceu em Fortaleza (CE), em 1983. (14) Marco Antonio foi julgado (15) e condenado. (16) Mas, só em 2001, 18 anos passados, e depois de ter recorrido a Justiça Internacional - Comissão Interamericana de Direitos Humanos, a OEA, (17) Maria da Penha conseguiu (18) que o ex-marido agressor fosse preso. 
A história generaliza sequências de ações ou episódios no decorrer do tempo cronológico, de 1983 a 2001, como a primeira e a segunda tentativa do marido agressor para assassinar a mulher, seguida da busca por justiça contra o homem que a agrediu.

Cada uma dessas ações pode ser constituída por uma sequência de microações. Por exemplo, a segunda tentativa, definida pela insistência do agressor em assassinar a esposa, acarreta em outras microações, como a eletrocução e a sobrevivência da mulher, que por sua vez reage e, graças ao fato de ter visto seu agressor, pôde testemunhar contra ele. Essa sequência de ações e reações constitui as práticas sociais. Nesse caso, a prática social está relacionada à violência doméstica e familiar contra a mulher.

Assim, na generalização das ações, a taxonomia de composição temporal pode ser representada por um esquema organizado por ações e microações do evento narrado em Crime infame: sobrevivi... posso contar.

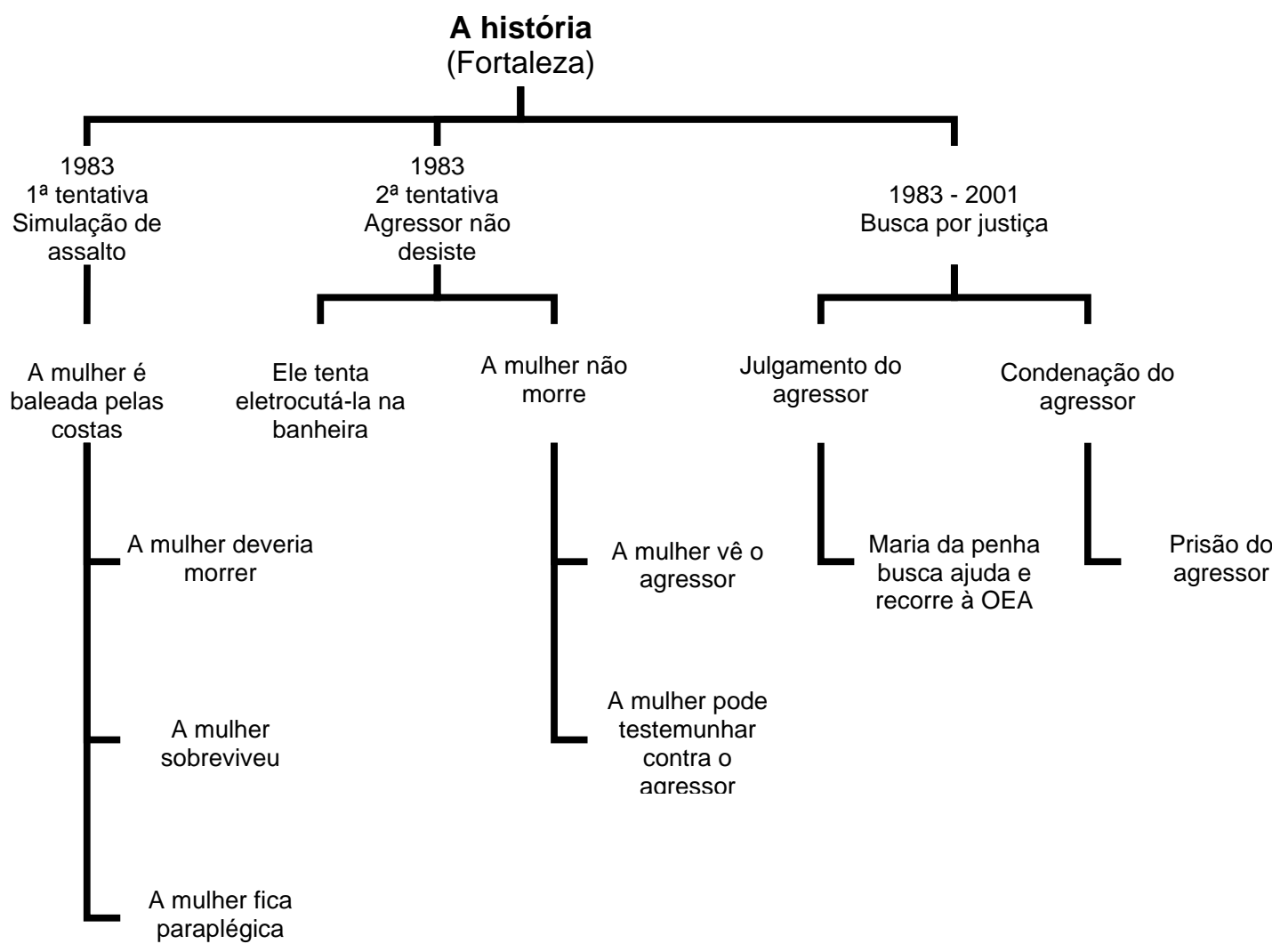

Taxonomia de Composição Temporal em Crime infame: sobrevivi... posso contar.

Na terceira e quarta parte do texto, a autora expõe sua opinião a respeito da violência cometida contra a mulher por seu companheiro, no âmbito doméstico e familiar. O Excerto 3 apresenta a terceira parte do texto, na qual é possível identificar 
claramente o predomínio do estatuto de subjetividade, por representar o posicionamento da autora.

\section{Excerto 3:}

(18) Em grau maior ou menor de violência, histórias como essa acontecem aos milhares, diariamente, no Brasil, em toda a América Latina, mundo afora. (19) Na maioria dos casos o agressor é o marido, o companheiro, o namorado, o amante. (20) $\mathrm{O}$ amor, que deveria ser 0 maior prêmio da vida, (21) embala essas tragédias (22) que alcançam pobres, remediados, ricos. (23) Nem todas são expostas. (24) Nem todas acabam em morte. (25) Mas a rotina de humilhações, agressões verbais e físicas, mesmo escondida, está mais próxima (26) do que imaginamos. (27) Não é revelada, principalmente, porque, além da dor, (28) a agredida sente muita vergonha.

Nesse fragmento, os atores sociais o agressor (19), e a agredida (28) estão generalizados, representados como classes, ou seja, a classe dos machões - homens que agridem, e a classe das submissas - mulheres frágeis que sofrem agressões e têm vergonha de se expor para denunciar seu companheiro. A representação dos atores por classes resulta na abrangência de um número maior de pessoas, o que contribui para o fortalecimento das mulheres agredidas, enquanto grupo, a fim de se conscientizarem que não são as únicas a sofrerem esse tipo de violência. A generalização é uma categoria de inclusão dos atores sociais como agentes no processo. Assim, quanto à ação social ocorre ativação.

O ator o agressor (19) generaliza uma classe e a mesma expressão (11) difere quanto à representação pela especificação de identidade de um único indivíduo. Com isso, uma mesma expressão pode cumprir diferentes papéis gramaticais e diferentes papéis sociais em diferentes momentos de um mesmo texto.

Na quarta parte do texto, Excerto 4, a autora mantém o estatuto de subjetividade, já que intensifica a representação da sua opinião sobre o assunto abordado.

\section{Excerto 4:}

(29) Maria da Penha, que viveu essa violência no limite máximo, (30) escreveu um livro: (31) Sobrevivi e (32) posso contar. (33) Mas, entre nós, há milhares de sobreviventes (34) que não revelam (35) o que viveram. (36) Se dá para esconder, (37) escondemos. (38) Encobrimos as marcas físicas, (39) tratamos com psicanálise e antidepressivos a dor no coração. (40) A vida segue. (41) A razão até perdoa, (42) mas a cicatriz é permanente. (43) Assombra como eterna indagação: por que a covardia?

A maneira como se realizam as representações de atores e de ações sociais no texto representam os propósitos da autora em relação ao seu público leitor, que são 
divulgar o livro escrito por Maria da Penha e criar questionamentos sobre a violência contra a mulher. Tendo em vista que o conteúdo desse texto é voltado às mulheres, principalmente àquelas preocupadas com a questão de violência a que são acometidas, pressupõe-se que público alvo seja o feminino.

Como uma maneira de se igualar a esse público, a autora se inclui na classe das mulheres que sofrem violência, fazendo uma distinção explícita entre os grupos de atores sociais, mulheres agredidas e homens agressores, por meio do pronome nós (33). Desse modo é estabelecida a oposição entre nós (33), que também está elíptico em outras orações subsequentes (37, 38, 39), e o agressor (19), generalizando a classe dos homens que agridem suas companheiras.

Em a razão até perdoa (41) e a cicatriz (expressão encoberta; na oração 42 desempenha o papel gramatical de atribuidor) assombra (43) há impersonalização, em que os atores sociais estão representados por uma referência metonímica. Com isso, a autora procura representar o impasse que as mulheres vivem diante das situações de violência em que podem estar envolvidas. $\mathrm{O}$ fato de muitas mulheres manterem silêncio sobre a violência sofrida é interpretado pela autora como uma covardia sem lógica.

\section{Conclusão}

A representação dos atores e das ações sociais consiste em uma das formas de observar a identidade social, com isso podem-se perceber as estratégias que atendem os propósitos do autor do texto, como destacar por inclusão ou, simplesmente, excluir os atores sociais em um texto.

O texto Crime infame: sobrevivi... posso contar sustenta a representação ideológica de gênero cultural. O homem é representado de uma forma negativa como o sexo forte e, por isso, mais agressivo verbal e fisicamente. A mulher é representada como o sexo frágil, mais emotiva, e deve, no coletivo, buscar alternativas para solucionar, ou pelo menos diminuir, o problema de violência que acomete sua classe.

Diante do exposto e das categorias analisadas, a partir das representações de atores e de ações sociais, foi possível realizar uma interpretação geral do texto, inclusive sobre os propósitos da autora subjacentes nas suas escolhas léxico-gramaticais.

\section{Referências Bibliográficas}


BRASIL. Lei Maria da Penha. Lei 11.340, de 7 de agosto de 2006. Presidência da República, Casa Civil, Subchefia para Assuntos Jurídicos. Disponível em: http://www.planalto.gov.br/CCIVIL/_Ato2004-2006/2006/Lei/L11340.htm Acesso em 28 de Abr. de 2009.

Lei Maria da Penha. Lei $n^{\circ} 11.340$ de 7 de agosto de 2006. Coíbe a violência doméstica e familiar contra a mulher. Presidência da República. Secretaria Especial de Políticas para as Mulheres (SEPM). Brasília, 2008. Disponível em: http://www.spmulheres.gov.br Acesso em 15 de Mai. de 2009.

Constituição da República Federativa do Brasil. Presidência da República, Casa Civil, Subchefia para Assuntos Jurídicos. 1988.

Código Penal. Decreto-lei n. 2.848, de 07 de dezembro de 1940. Presidência da República. Disponível e: http://planalto.gov.br/CCIVIL/Decreto-Lei/Del2848.htm Acesso em 12 de Mai. de 2009.

DE CONTO, J. M. O Sistema de Gêneros da Seleção de Candidatos a Emprego no Contexto Empresarial. Dissertação (Mestrado em Letras). Santa Maria, UFSM, 2008.

FAIRCLOUGH, N.; MAGALHÃES, I. (coordenadora da tradução, revisão técnica e prefácio). Discurso e Mudança Social. Brasília: Ed. Univ. de Brasília, 2001.

FUSCO, T. Crime Infame: sobrevivi... posso contar. O Globo. 25 de Nov. de 2005. Disponível em: http://www.oglobo.globo/pais/noblat Acesso em 24 de Mai. de 2009.

FUZER, C. e BARROS, N. C. Processo Penal como Sistema de Gêneros. Linguagem em (Dis)curso, v. 8, nº 1, jan. / abr, pp. 43-64, 2004.

FUZER, C. Linguagem e representação nos autos de um processo penal: como operadores do direito representam atores sociais em um sistema de gêneros. Santa Maria: UFSM, 2008. Tese (Doutorado em Letras), Universidade Federal de Santa Maria, Santa Maria, 2008.

HALLIDAY, M. A. K. e HASAN, R. Language, context and text: aspects of language in a social perspective. Oxford: Oxford University Press, 1989.

HALLIDAY, M. A. K. e MATTHIESSEN, C. An introduction to functional grammar. London: Edward Arnold, 2004.

IKEDA, S. N. \& VIAN Jr., O. (no prelo). A análise do discurso pela perspectiva sistêmico-funcional. In: LEFFA, V. J. (Org.). Pesquisa em lingüística aplicada: temas e métodos. Pelotas: Educat, 2006. p. $31-69$.

MARTIN, J. R. e ROSE, D. Working with Discourse: meaning beyond the clause. London - New York: Continuum, 2003. 
MOTTA-ROTH, D. \& HEBERLE, V. O conceito de "estrutura potencial do gênero" de Ruqayia Hasan. In: MEURER, J. L., BONINI, A. \& MOTTA-ROTH, D. (Orgs.) Gêneros, teorias, métodos e debates. São Paulo: Parábola Editorial, 2005. p. 12 - 28.

PEREIRA, J. S. \& ALMEIDA, M. B. “Sabe tudo sobre tudo": análise da seção de cartas-pergunta em revistas femininas para adolescentes. In: MEURER, J. L. \& MOTTA-ROTH, D. (orgs.). Gêneros textuais e práticas discursivas: subsídios para 0 ensino da linguagem. Bauru, SP: EDUSC, 2002. p. 239 - 258.

VAN LEEUWEN, T. "The Representing of Social Actors”. In: VAN LEEUWWEN, Discourse and Practice: new tools for critical discourse analysis. New York: Oxford University Press, 2008. pp. 23-54.

"The Representing Social Action". In: VAN LEEUWWEN, Discourse and Practice: new tools for critical discourse analysis. New York: Oxford University Press, 2008. pp. 55-74.

\section{Anexo}

O Globo - blog do Noblat

Enviado por Ricardo Noblat

25.11.2005 | 12h00m

\section{CRIME INFAME - Sobrevivi e posso contar (Por Tânia Fusco)}

Primeiro ele simulou um assalto na casa onde a mulher foi baleada pelas costas. Ela deveria ter morrido, mas sobreviveu paraplégica. Ele não desistiu. Tentou eletrocutá-la na banheira. De novo ela não morreu e, dessa vez, viu e pode testemunhar que o agressor era o próprio marido, Marco Antonio Herredia Viveiros, colombiano, professor universitário de economia, pai dos três filhos da biofarmacêutica Maria da Penha Fernandes.

A história aconteceu em Fortaleza (CE), em 1983. Marco Antonio foi julgado e condenado. Mas, só em 2001, 18 anos passados, e depois de ter recorrido a Justiça Internacional -- Comissão Interamericana de Direitos Humanos, a OEA, Maria da Penha conseguiu que o ex-marido agressor fosse preso. Em grau maior ou menor de violência, histórias como essa acontecem aos milhares, diariamente, no Brasil, em toda a América Latina, mundo afora. Na maioria dos casos o agressor é o marido, o companheiro, o namorado, o amante. O amor, que deveria ser o maior prêmio da vida, embala essas tragédias que alcançam pobres, remediados, ricos. Nem todas são expostas. Nem todas acabam em morte. Mas a rotina de humilhações, agressões verbais e físicas, mesmo escondida, está mais próxima do que imaginamos. Não é revelada, principalmente, porque, além da dor, a agredida sente muita vergonha. Maria da Penha, que viveu essa violência no limite máximo, escreveu um livro: Sobrevivi e posso contar. Mas, entre nós, há milhares de sobreviventes que não revelam o que viveram. Se dá para esconder, escondemos. Encobrimos as marcas físicas, tratamos com psicanálise e antidepressivos a dor no coração. A vida segue. A razão até perdoa, mas a cicatriz é permanente. Assombra como eterna indagação: por que a covardia? 